\title{
Forecasting Sclerotinia Disease on Lettuce: A Predictive Model for Carpogenic Germination of Sclerotinia sclerotiorum Sclerotia
}

\author{
John P. Clarkson, Kath Phelps, John M. Whipps, Caroline S. Young, Julie A. Smith, and Martyn Watling
}

First, second, and third authors: Warwick HRI, University of Warwick, Wellesbourne, CV35 9EF, UK; fourth author: ADAS UK Ltd., Defra Drayton, Alcester Road, Stratford on Avon, Warwickshire CV37 9RQ, UK; fifth author: ADAS UK Ltd., ADAS Wolverhampton, Woodthorne, Wergs Road, WV6 8TQ, UK; and sixth author: ADAS UK Ltd., ADAS Terrington, Terrington St. Clement, King's Lynn, Norfolk PE34 4PW, UK.

Accepted for publication 10 November 2006.

\begin{abstract}
Clarkson, J. P., Phelps, K., Whipps, J. M., Young, C. S., Smith, J. A., and Watling, M. 2007. Forecasting sclerotinia disease on lettuce: a predictive model for carpogenic germination of Sclerotinia sclerotiorum sclerotia. Phytopathology 97:621-631.

A predictive model for production of apothecia by carpogenic germination of sclerotia is presented for Sclerotinia sclerotiorum. The model is based on the assumption that a conditioning phase must be completed before a subsequent germination phase can occur. Experiments involving transfer of sclerotia from one temperature regime to another allowed temperature-dependent rates to be derived for conditioning and germination

for two $S$. sclerotiorum isolates. Although the response of each isolate to temperature was slightly different, sclerotia were fully conditioned after 2 to 6 days at $5^{\circ} \mathrm{C}$ in soil but took up to 80 days at $15^{\circ} \mathrm{C}$. Subsequent germination took more than 200 days at $5^{\circ} \mathrm{C}$ and 33 to 52 days at $20^{\circ} \mathrm{C}$. Upper temperature thresholds for conditioning and germination were 20 and $25^{\circ} \mathrm{C}$, respectively. A predictive model for production of apothecia derived from these data was successful in simulating the germination of multiple burials of sclerotia in the field when a soil water potential threshold of between -4.0 and -12.25 kilopascals $(\mathrm{kPa})$ was imposed. The use of a germination model as part of a disease forecasting system for Sclerotinia disease in lettuce is discussed.
\end{abstract}

Sclerotinia sclerotiorum (Lib.) de Bary is a nectrotrophic pathogen with world-wide distribution known to infect over 400 species of plants (5). Sclerotinia disease affects many crops in the United Kingdom, particularly lettuce, oilseed rape, and more recently, carrot. The sclerotia of the pathogen survive in soil for several years and infect the majority of hosts indirectly, by germinating to produce apothecia which then release ascospores $(4,18,20)$. Hence, apothecial production through carpogenic germination of sclerotia is a fundamental part of the pathogen's life cycle.

Currently, control of Sclerotinia disease on lettuce relies on the application of fungicides to prevent infection by ascospores. However, limits on the permitted number of sprays make it essential to time applications effectively in order to control disease and avoid prophylactic spraying. One way to address this is to develop a Sclerotinia disease forecasting system. Several forecasting systems have been developed, as reviewed by McDonald and Boland (15) and McLaren et al. (16), with the focus on oilseed rape (canola) and bean. These have largely used risk-point tables based on risk of apothecium development, soil moisture, temperature, and crop factors such as canopy development, as well as previous cropping and disease levels. The component of apothecium development risk in all these models is often based on field observations of apothecia, which has been shown to improve accuracy of predictions for Sclerotinia disease on bean (15). However, the time and effort involved in gathering all the data for risk-point tables and in monitoring appearance of apothecia in the field has meant that none of these systems are in regular use. In a previous study we developed a model to describe carpogenic germination

Corresponding author: J. P. Clarkson

E-mail address: john.clarkson@warwick.ac.uk

doi:10.1094/PHYTO-97-5-0621

(c) 2007 The American Phytopathological Society and appearance of apothecia based on effects of soil temperature and water potential (7), with the aim of timing fungicide sprays for periods when ascospores were present, in order to control Sclerotinia disease on lettuce. It was found that germination occurred between 5 and $20^{\circ} \mathrm{C}$ but only for soil water potentials $\geq-100 \mathrm{kPa}$ with little or no germination at or above $25^{\circ} \mathrm{C}$, or at approximately $-300 \mathrm{kPa}$. These results concurred with another recent study (12) although other workers have reported different optimum temperatures for germination $(1,25)$. The reported soil water potential threshold for germination is also variable, but generally, researchers agree that moist (but not saturated) soil is required (20).

In our previous study (7) we used a simple thermal time approach incorporating temperature and water potential thresholds to predict the appearance of apothecia from sclerotia buried in the field at regular intervals during the year. However, results were not satisfactory, as the best prediction of germination occurred when an upper temperature threshold of $16^{\circ} \mathrm{C}$ was imposed on the model, which was contrary to the reported 25 to $30^{\circ} \mathrm{C}$ range $(1,7,12,25)$. Furthermore, the thermal time model could not account for the poor or nongermination of sclerotia buried from mid-May to September. We hypothesize that these discrepancies may be due to the effect of the conditioning treatment given to the sclerotia before burial, which involves exposing them to low temperature in order to stimulate or accelerate production of apothecia $(13,17,19,21,24)$. Sclerotia in our previous experiments were produced on wheat grain at $20^{\circ} \mathrm{C}$ and given a standard conditioning treatment of 28 days at $4^{\circ} \mathrm{C}$ before burial in the field. However, if this was an inadequate period for complete and effective conditioning, the sclerotia would require further exposure to cold temperatures in order to complete this phase before they could germinate quickly. This might, then, explain the low upper temperature threshold of $16^{\circ} \mathrm{C}$ in our thermal time model and the observed nongermination of sclerotia when buried from early summer onwards (no exposure to cold temperatures). 
The overall aim of this study was, therefore, to produce and test an improved model for prediction of carpogenic germination in the field through a better understanding of conditioning and germination, and, by deriving mathematical relationships, to describe the effect of temperature on these processes for two S. sclerotiorum isolates collected in the United Kingdom.

\section{MATERIALS AND METHODS}

Isolates and production of sclerotia. Two isolates of S. sclerotiorum derived from sclerotia collected from diseased lettuce plants were used in this study. Isolate 13 (IMI 390053) originated from lettuce grown on a Cheshire peat soil (Turbary Moor Series) and isolate TM (IMI 390054) originated from plants on a Norfolk silty clay loam (Blacktoft Series). Original isolations and selection of these two isolates have been described previously (7). Stock sclerotia of each isolate were produced on potato dextrose agar (PDA) (Merck, UK) and stored under sterile conditions at $5^{\circ} \mathrm{C}$. To produce large numbers of sclerotia for experiments, stock sclerotia were bisected, placed on PDA and incubated for 4 to 7 days at $20^{\circ} \mathrm{C}$. Agar plugs (approximately $3 \mathrm{~mm}^{2}$ ) taken from the edge of actively growing mycelium were then used to inoculate sterile wheat grain $(25 \mathrm{~g}$ wheat grain, $50 \mathrm{~g}$ water autoclaved at $121^{\circ} \mathrm{C}$ for $15 \mathrm{~min}$ ) in $500-\mathrm{ml}$ conical flasks. Flasks were incubated at $20^{\circ} \mathrm{C}$ for 4 weeks, after which sclerotia had formed and matured. In some experiments, flasks were then placed at $4^{\circ} \mathrm{C}$ as a cold-conditioning treatment for the sclerotia to promote carpogenic germination $(17,21)$. Sclerotia between 2 and $5 \mathrm{~mm}$ in diameter were recovered by wet sieving and floating off the wheat grain. Finally, the sclerotia were dried in an air-flow hood overnight after which they were immediately used in experiments.

Effect of temperature on conditioning and germination of sclerotia. A series of laboratory experiments was conducted to determine the effect of temperature on conditioning and germination of $S$. sclerotiorum sclerotia from isolates 13 and TM. The two processes were assumed to be sequential with completion of the conditioning phase necessary before germination could occur. All experiments, therefore, involved transfer of sclerotia between two temperatures (Stage 1 and Stage 2 temperatures as described below) and monitoring subsequent appearance of apothecia. Stage 1 largely represented the conditioning phase while Stage 2 mainly represented the germination phase. However, depending on the temperature and duration of Stage 1, germination might occur before the end of this stage or conditioning could still be continuing at the start of Stage 2. Data collected from these experiments were used to derive temperature-dependent rates of conditioning and germination phases. Experiment 1 was set up to determine the effect of temperature on time to germination in soil (Stage 2) of sclerotia grown on wheat grain and then incubated for different durations at $4^{\circ} \mathrm{C}$ (Stage 1). These data would also allow the degree of conditioning to be calculated for sclerotia given our standard treatment of $28 \mathrm{~d}$ at $4^{\circ} \mathrm{C}$. However, as conditioning sclerotia in flasks with wheat grain is an artificial system, Experiments 2 and 3 tested a matrix of temperature regimes for Stages 1 and 2 for sclerotia buried in soil. As it was shown previously that soil water potential must be above $-100 \mathrm{kPa}$ for carpogenic germination (7), soil water content was standardized in all experiments at $-9 \mathrm{kPa}$.

Experiment 1. Sclerotia of isolates 13 and TM produced on wheat grain in flasks at $20^{\circ} \mathrm{C}$ were incubated at $4^{\circ} \mathrm{C}$ for $0,14,16$, 42, 58, 79, 101, 133, 213, 252, 345, and 417 days (Stage 1). Sclerotia were then harvested, dried, and buried in clear plastic 600-ml boxes (Malsar Kest Ltd., London) with clip-on lids. These boxes contained the peat soil (isolate 13) or the silty clay loam (isolate TM) at a depth of $1 \mathrm{~cm}$ and at temperatures of 10, 13, 15, or $18^{\circ} \mathrm{C}$ (Stage 2). Boxes were placed in growth cabinets with white fluorescent lighting ( $12 \mathrm{~h}$ day; $20 \mathrm{~W} / \mathrm{m} 2)$ and monitored for germination of sclerotia to produce stipes or apothecia once or twice a week for up to 300 days. For each Stage 1/Stage 2 treatment there were three replicate boxes, each containing 30 sclerotia arranged in a grid pattern. Carpogenic germination of sclerotia to produce stipes or apothecia was recorded once or twice a week.

Experiment 2. Sclerotia of isolates 13 and TM produced on wheat grain were buried in bulk batches (110 sclerotia in mesh bags at $3 \mathrm{~cm}$ depth) in the peat soil (isolate 13 ) or silty clay loam (isolate TM) for 30, 50, 75, and 100 days at 4, 7, 10, 13, 15, and $20^{\circ} \mathrm{C}$ (Stage 1). After this period, sclerotia were retrieved and reburied at a depth of $1 \mathrm{~cm}$ in clear plastic boxes containing the peat or silty clay loam at $15^{\circ} \mathrm{C}$ (Stage 2) in a growth cabinet with white fluorescent lighting. As before, there were three replicate boxes containing 30 sclerotia for each treatment and germination was recorded for up to 225 days.

Experiment 3. Sclerotia of isolates 13 and TM were buried in mesh bags in soil as in Experiment 2 for 0, 15, 30, 50, 75, and 100 days at $4^{\circ} \mathrm{C}$ (Stage 1). After this period sclerotia were retrieved and buried in boxes containing the peat or silty clay loam at $10,13,15,18$, and $25^{\circ} \mathrm{C}$ (Stage 2) in growth cabinets with white fluorescent lighting. As before, there were three replicate boxes containing 30 sclerotia for each treatment and germination was recorded for up to 195 days.

Apothecial production by sclerotia in the field. Experiments were carried out to generate multiple germination data sets under different environmental conditions for S. sclerotiorum sclerotia buried in the field. These data were then used to test the predictive model for carpogenic germination derived from laboratory experiments and added to similar data collected in 2000 and 2001 (7). Sclerotia of isolates 13 and TM were buried in bare soil at field sites in Rixton, Cheshire, and Terrington, Norfolk, UK, every 2 to 4 weeks from March to August 2003, from January to October 2004, and from January to June 2005. In addition, winter burials of sclerotia were made in December 2002, 2003, and 2004 for monitoring the following year. The sites corresponded to the original soil type and location of each $S$. sclerotiorum isolate and regular burials ensured sclerotia were exposed to a wide range of environmental conditions. Sclerotia from each isolate were produced and conditioned on wheat grain for 28 days at $4{ }^{\circ} \mathrm{C}$ as described previously except for sclerotia buried in 2005 , which were unconditioned. For each burial, a total of 400 sclerotia were buried at a depth of approximately $1 \mathrm{~cm}$ in grids laid over the soil surface at each location (4 grids of 100 sclerotia). Grids were arranged in a randomized block design. The appearance of apothecia was recorded once or twice a week, and a sclerotium was considered to have germinated when one or more apothecia had been recorded in a grid cell. Germination was monitored until the end of October each year. Environmental conditions were recorded every 30 min using a data logger (Delta-T Instruments, Cambridge, UK) with probes recording rainfall (RG1 tipping bucket rain gauge), soil temperature (standard thermistor probe, five per field site), and soil water content ([ML2X ThetaProbe, Delta Instruments] five per field site). Raw output from the theta probe $(\mathrm{mV})$ was converted to water content using a relationship derived by recording theta probe measurements for a range of known soil water contents. Soil water content was then converted to soil water potential using a soil moisture release curve for each soil type, obtained by desorption of saturated soil in a standard pressure plate apparatus. At each burial time, duplicate samples of sclerotia-two bags, each containing 25 sclerotia-were also buried at a depth of $10 \mathrm{~cm}$ in a mesh bag adjacent to the grid area. Six weeks after each burial, these sclerotia were retrieved and checked for degradation by counting those remaining after rubbing over a 2-mm sieve to remove any that were soft and degraded.

Statistical analyses. Analyses were based on the cumulative number of sclerotia that had germinated over time for Experiments 1 to 3 . Normal and lognormal distributions were fitted to the cumulative germination curves for each temperature regime. The lognormal distribution implies that the logarithm of times to 
germination follows a normal distribution whose parameters relate to the mean germination time as follows (equation 1):

$$
M=\exp \left(m+0.5 s^{2}\right)
$$

where $M$ is the mean time to germination (equivalent to the time taken for $50 \%$ of the population to germinate) and $\mathrm{m}$ and $\mathrm{s}$ are the mean and standard deviation of the corresponding normal distribution. Mean times to germination $(M)$ for the lognormal distribution were calculated for each treatment regime examined in the experiments. Analysis of the data was by analysis of variance on the summary statistics, with times to germination transformed to rate (inverse of time). Each analysis included both $S$. sclerotiorum isolates, thus generating high-order interactions to be used as error terms. Duration at Stage 1 and temperature effects were partitioned into linear and quadratic terms, and $\mathrm{F}$ tests on the variance ratios were used to identify the important trends. All effects described in the results are significant at $P<0.001$.

A predictive model for germination of $S$. sclerotiorum sclerotia. A mathematical model was formulated to describe the timing of carpogenic germination for a population of S. sclerotiorum sclerotia. The model assumes that a conditioning phase must be completed before germination can occur with the rates of both processes being solely dependent on temperature when soil moisture is not limiting. In the model, the mean time to germination ( $M$, equation 1$)$ is predicted by numerical integration of two functions representing temperature-dependent rates of conditioning and germination. Time to germination of any fraction of the sclerotial population is then calculated from the lognormal distribution (with mean $M$ ) assuming a given value of $s$ (equation 1). This type of modeling approach has previously been used in twostage population models to describe germination of small seeds $(2,10)$.

The equations for temperature-dependent conditioning and germination rates within the germination model were derived using data from Experiments 2 and 3 in two optimization procedures. The first procedure indicated the form of the equations, where a complex model based on separate values for conditioning and germination rates at different temperatures was formulated with the only constraint that rates were $>0$. This complex model was designed to be flexible enough to allow conditioning and germination relationships with temperature to be any shape; for instance, they could be monotonically increasing or decreasing or could have one or more temperature-related optima. The model had 16 parameters in total (8 parameters corresponding to temperatures $4,7,10,13,15,18,20$, and $25^{\circ} \mathrm{C}$ for conditioning and germination phases) and was fitted to the mean times to germination observed in Experiments 2 and 3 using maximum likelihood within the 'fitnonlinear' directive in GenStat (version 7, VSN Int. Ltd., Hemel Hempstead, UK).

The second procedure involved replacing the complex model with a simpler version with fewer parameters. The properties of the simpler model were identified by plotting the 8 estimated conditioning and germination rates against their corresponding temperatures. This process indicated that i) the rate of conditioning could be represented by a modified exponential curve (equation 2):

$$
r_{c}=a+b e^{-k T}
$$

where $r_{\mathrm{c}}$ is rate of conditioning per day, $a, b$, and $k$ are constants, and $T$ is temperature $\left({ }^{\circ} \mathrm{C}\right)$, and that ii) the rate of germination could be represented by an Arrhenius curve (equation 3 ):

$$
r_{g}=\exp \left(\frac{d_{0}+d_{1}}{T+273}\right)
$$

Where $r_{\mathrm{g}}$ is rate of germination per day, $d_{0}$ and $d_{1}$ are constants, and $T$ is temperature $\left({ }^{\circ} \mathrm{C}\right)$.

The final germination model therefore consisted of two functions describing the effect of temperature on rate of conditioning and germination (equations 2 and 3). This simpler model was fitted to the mean times to germination observed in Experiments 2 and 3 using GenStat as before, and values for the five parameters were estimated. The goodness of fit could only be shown for the model as a whole and not for its constitutive conditioning and germination components, as the endpoint of conditioning could not be observed directly through experiments. The fit of the germination model was therefore compared with observed mean germination times in Experiments 2 and 3. Briefly, this involved calculating the fraction of conditioning and germination achieved at the end of Stage 1 for each temperature regime from the predicted time for completion of each process at a given temperature (equations 2 and 3). The time for the remaining fraction of one or both processes was then calculated for Stage 2 to give a predicted mean germination time.

Testing the model for germination of sclerotia using field data. The germination model was tested using 5 years of field data for isolates 13 (Cheshire field site) and TM (Norfolk field site) where sclerotia were buried at different times and germination to produce apothecia monitored (2000, 2001, 2003, 2004, 2005). Data for 2000 and 2001 have been published previously (7). Simulation curves to describe the observed cumulative germination of sclerotia in the field were produced by applying the model to the soil temperature and water potential data recorded by the logger. Predicted times generated by the model for $10 \%$ (T10) and 50\% (T50) germination of sclerotia for each burial from the model were then compared with the corresponding observed times in the field and analyzed with a chi-square test. The procedures involved in applying the model were as follows: (i) calculation of the degree of conditioning for sclerotia buried in the field; (ii) simulation of germination curves for burials of sclerotia in the field and calculation of predicted mean germination times; and (iii) application of temperature and water potential thresholds.

i) Calculation of the degree of conditioning for sclerotia buried in the field. In all years except 2005, sclerotia were conditioned in flasks ( 28 days at $4^{\circ} \mathrm{C}$ in wheat grain) before burial in the field. Hence, before the germination model could be applied, an estimate of the degree of conditioning achieved during this time was required for each $S$. sclerotiorum isolate. This was deduced by applying the relationship between temperature and germination rate in soil (equation 3) to the data in Experiment 1 so that the fraction of the germination process $\left(f_{2}\right)$ achieved after sclerotia were removed from the flasks and buried in soil at different temperatures (Stage 2, Experiment 1) could be calculated. The degree of conditioning and germination that occurred in the flasks was then calculated for the different durations at $4^{\circ} \mathrm{C}$ (Stage 1, Experiment 1) using the following relationship:

$$
t_{1}=c_{4}+\left(1-f_{2}\right) g_{4}
$$

Where $t_{1}$ is the duration of Stage 1 and $c_{4}$ and $g_{4}$ are the times (days) to condition and germinate, respectively, at $4^{\circ} \mathrm{C}$ in wheat grain. Linear regression of $t_{1}$ on $\left(1-f_{2}\right)$ allowed $c_{4}$ and $g_{4}$ to be estimated. As the total time for conditioning is $c_{4}$, then the fraction of conditioning achieved during the 28 days at $4{ }^{\circ} \mathrm{C}$ for each isolate can be estimated as $28 / c_{4}$. The derived conditioning and germination rates in flasks were tested by applying them to the different Stage 1 durations at $4^{\circ} \mathrm{C}$ in Experiment 1 with the appropriate subsequent germination rate in soil (equation 3 ) and comparing these fitted germination times with the observed germination times for sclerotia from $S$. sclerotiorum isolates 13 and TM.

ii) Simulation of germination curves for burials of sclerotia in the field and calculation of predicted germination times. The weather data collected from the field and used to run the germination model were soil temperature and water potential recorded at half-hourly intervals. The conditioning part of the model (equa- 
tion 2) was applied to soil temperature data in order to calculate the progress of this phase by accumulating the rates per half-hour from each temperature record. Soil temperature and water potential thresholds were applied as described in iii) below and conditioning was assumed to be complete when the accumulated rates reached a value of 1 . As sclerotia buried in the field were conditioned in all years except 2005, the starting value for accumulating conditioning rates was set to the fraction of conditioning achieved calculated in i). As sclerotia were not conditioned in 2005 , the starting value in this year was set to a value of 0 . Once conditioning was predicted to be complete, germination rates (equation 3) were accumulated using the half-hourly temperature records, again with soil temperature and water potential thresholds applied as in iii). Germination was assumed to be complete at time $M$ (equation 1 ) when this accumulation reached 1 . To produce simulation curves to compare with the observed cumulative germination of buried sclerotia in the field, the variability in the germination times of sclerotia was quantified using data from Experiment 3. The relationship between the standard deviation and the mean of the logarithm of germination times for these data ( $s$ and $m$, equation 1) was studied to give an estimate of $s$. In order to generate a frequency distribution for each burial of sclerotia in the field, equation 1 was rearranged to calculate $m$ from this value of $s$ and the simulated values of $M$. Based on this, simulation curves for comparison with observed data were produced by calculating the percentage of sclerotia predicted to have germinated at each recording time. Predicted T10 and T50 times for germination were also calculated for comparison with the observed germination times for all the burials of sclerotia.

iii) Application of temperature and water potential thresholds. It was clear from the results in Experiments 2 and 3 and also from previous work $(1,7,9,12,25)$ that upper temperature thresholds and a lower water potential threshold should be applied to the rates of conditioning and germination of $S$. sclerotiorum sclerotia when applying the model. Hence, the rates accumulated in ii) were set to zero above an upper temperature limit and below a lower water potential limit. Initially, the temperature and soil water potential thresholds tested were deduced from the laboratory data and previous work but this was unsatisfactory for soil water potential. The water potential threshold that gave the best predictions for each $S$. sclerotiorum isolate in each year was therefore derived by running the germination model with a range of water potential thresholds at $0.25 \mathrm{kPa}$ intervals. The predicted mean times for germination generated by the model were then compared with the equivalent observed mean times of the buried sclerotia and the residual mean square error (RMSE) calculated from the difference between the observed and predicted values for each burial in each year as follows:

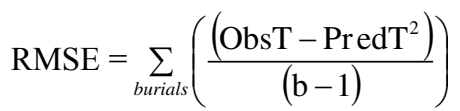

where ObsT $=$ observed time (days) to $\mathrm{T} 50$, PredT $=$ predicted time (days) to T50 ( $M$, equation 1$)$, and $\mathrm{b}=$ number of burials of sclerotia where $\geq 50 \%$ germination was achieved. A smaller value in RMSE indicates a better prediction. The water potential value which minimized the RMSE was hence chosen as the optimum threshold value. For certain burials in some years, satisfactory predictions could not be made because the predicted mean time was beyond the end of the recording period and hence no weather data were available.

\section{RESULTS}

Effect of temperature on conditioning and germination of sclerotia. Overall, the lognormal distribution provided a good fit for almost all the germination curves in Experiments 1 to 3. It was possible to fit both the lognormal and normal distributions for 222 of 231 data sets, with the lognormal distribution fitting better than the normal distribution in $77 \%$ of cases. In a few cases, where germination was poor or very slow, the lognormal distribution could not be fitted and hence a mean time to germination $(M$, equation 1) could not be calculated. These treatments are indicated in the results of each experiment. Inspection of parameter $s$ indicated that it was relatively constant $(s=0.1417)$ for all values of $m$ for both $S$. sclerotiorum isolates (equation 1 ).

Experiment 1. Overall, longer durations at $4^{\circ} \mathrm{C}$ in wheat grain (Stage 1) resulted in fewer days to germination at the Stage 2 temperatures tested $\left(10,13,15\right.$, and $\left.18^{\circ} \mathrm{C}\right)$ for $S$. sclerotiorum sclerotia (Table 1). This trend was highly consistent for both isolates, with germination times ranging from 196 days for unconditioned sclerotia, to 19 days after 417 days at Stage 1 over all Stage 2 temperatures. However, there was little decrease in time to germination for periods beyond 100 days at $4^{\circ} \mathrm{C}$. Stage 2 temperature also had a big effect, with mean germination times decreasing between 10 and $18^{\circ} \mathrm{C}$ for both isolates. It was also noted that no germination of sclerotia ever occurred in the wheat grain flasks, even for those held at $4^{\circ} \mathrm{C}$ for more than 400 days.

Experiment 2. The mean time to germination of sclerotia at $15^{\circ} \mathrm{C}$ (Stage 2) decreased significantly with duration of Stage 1 in soil, and increased with Stage 1 temperature (Table 2). Shortest germination times occurred during 100 days' duration at Stage 1 at 4 to $10^{\circ} \mathrm{C}$, during which time isolate 13 took 36 to 40 days to germinate and TM took 53 to 72 days. For isolate 13, germination began during Stage 1 at 13 and $15^{\circ} \mathrm{C}$ during 100 days' duration, so accurate mean times to germination could not be derived, as monitoring did not occur during this period. For isolate TM, poor

TABLE 1. Mean time to germination for sclerotia of Sclerotinia sclerotiorum isolates 13 and $\mathrm{TM}$ at $10,13,15$, and $18^{\circ} \mathrm{C}$ (Stage 2 ) after different durations at $4^{\circ} \mathrm{C}$ (Stage 1) in Experiment 1

\begin{tabular}{|c|c|c|c|c|c|c|c|c|}
\hline \multirow[b]{2}{*}{ Days at $4^{\circ} \mathrm{C}$} & \multicolumn{4}{|c|}{ Isolate $13^{\mathrm{a}}$} & \multicolumn{4}{|c|}{ Isolate $\mathrm{TM}^{\mathrm{a}}$} \\
\hline & $10^{\circ} \mathrm{C}$ & $13^{\circ} \mathrm{C}$ & $15^{\circ} \mathrm{C}$ & $18^{\circ} \mathrm{C}$ & $10^{\circ} \mathrm{C}$ & $13^{\circ} \mathrm{C}$ & $15^{\circ} \mathrm{C}$ & $18^{\circ} \mathrm{C}$ \\
\hline 0 & $194.7(2.8)$ & $193.5(6.2)$ & $149.6(3.9)$ & $73.0(3.0)$ & $166.4(0.2)$ & $157.8(1.9)$ & $195.6(8.2)$ & $108.7(8.6)$ \\
\hline 14 & $167.0(25.2)$ & $157.8(2.5)$ & $\ldots$ & $55.1(1.9)$ & $142.4(4.7)$ & $138.7(6.5)$ & $143.4(13.9)$ & $95.2(9.3)$ \\
\hline 16 & $137.0(6.6)$ & $125.5(4.1)$ & $102.9(6.8)$ & $74.8(3.7)$ & $168.6(6.6)$ & $179.4(17.4)$ & & $83.0(9.5)$ \\
\hline 42 & $113.3(5.2)$ & $103.2(4.5)$ & $74.6(3.3)$ & $39.9(1.0)$ & $117.9(1.7)$ & $121.0(3.1)$ & $108.2(3.3)$ & $53.5(4.2)$ \\
\hline 58 & $85.1(6.3)$ & 72.5 (6.6) & $50.7(3.1)$ & $45.8(2.6)$ & $118.4(3.5)$ & $119.4(17.5)$ & $99.6(18.1)$ & $47.2(3.1)$ \\
\hline 79 & $79.2(2.7)$ & $61.4(3.3)$ & $59.3(7.4)$ & $28.7(4.2)$ & $79.6(1.4)$ & $64.0(1.5)$ & $52.8(2.9)$ & $35.6(0.8)$ \\
\hline 101 & $78.8(2.5)$ & $64.0(4.1)$ & $50.6(2.7)$ & $24.6(2.2)$ & $61.5(1.2)$ & $46.3(1.5)$ & $36.3(1.3)$ & $34.9(1.4)$ \\
\hline 133 & $49.0(0.7)$ & $34.9(0.5)$ & $33.1(0.4)$ & $39.1(5.6)$ & $70.3(1.0)$ & $43.8(0.6)$ & $36.6(0.3)$ & $38.0(0.9)$ \\
\hline 213 & $44.2(2.0)$ & $31.7(1.5)$ & $32.2(1.5)$ & $38.8(6.4)$ & $56.1(2.6)$ & $43.7(1.4)$ & $37.5(2.0)$ & $45.0(2.2)$ \\
\hline 252 & $30.9(0.8)$ & $25.0(0.5)$ & $27.5(1.6)$ & $30.6(4.7)$ & $58.0(0.9)$ & $40.9(0.5)$ & $33.7(0.2)$ & $36.6(1.7)$ \\
\hline 345 & $49.8(2.9)$ & 40.7 (1.7) & $32.7(3.2)$ & $36.2(10.2)$ & $49.4(0.8)$ & $36.7(0.6)$ & $31.2(0.5)$ & $34.2(1.3)$ \\
\hline 417 & $30.8(2.4)$ & 26.9 (1.9) & $21.0(1.4)$ & $19.0(1.9)$ & $41.5(2.1)$ & $33.6(1.0)$ & $33.1(1.4)$ & 27.7 (1.6) \\
\hline
\end{tabular}

${ }^{a}$ Data are mean germination times (days) for three replicates of 30 sclerotia. Standard error of the mean (fitted from the lognormal distribution) in parentheses. Dots represent missing values. 
germination $(<50 \%)$ following Stage 1 durations of 30 and 50 days at $15^{\circ} \mathrm{C}$ meant that mean times to germination were also not derived for these treatments.

Experiment 3. The mean time to germination of sclerotia decreased significantly with Stage 2 temperature for all Stage 1 durations in soil at $4{ }^{\circ} \mathrm{C}$ (Table 2). Shortest germination times were for 100 days' duration at Stage 1, followed by Stage 2 temperatures of $>15^{\circ} \mathrm{C}$, at which isolate 13 took 22 to 28 days to germinate and TM took 47 to 50 days. For Stage 1 durations $>0$ days, there was generally a decrease in time to germination with increasing exposure to $4{ }^{\circ} \mathrm{C}$, but this was only significant for isolate 13 . If sclerotia had no time at $4^{\circ} \mathrm{C}$ (i.e., stage 1 duration $=0$, no conditioning), times to germination in Stage 2 were very long ( $>75$ days) and often final germination was less than $50 \%$, meaning that mean germination times could not be derived. This occurred for Stage 2 temperatures of $10^{\circ} \mathrm{C}$ for isolate 13 and at 10,13 , and $18^{\circ} \mathrm{C}$ for isolate TM. Germination was also $<50 \%$ for most treatments where Stage 2 temperature was $25^{\circ} \mathrm{C}$, which again limited the data set (Table 2).

Apothecial production by sclerotia in the field. Germination of sclerotia from isolates 13 and TM to produce apothecia at both field sites in 2003, 2004, and 2005 followed a similar pattern to that observed previously (7). Apothecia from winter burials (2003 to 2005) made in December the previous year, and early season burials made until May, were first seen within 66 to 156 days (isolate 13) and 93 to 191 days (isolate TM), and final percentage germination was generally $>60 \%$ for isolate 13 and $>10 \%$ for isolate TM. Final percentage germination was also consistently greater for isolate 13 (maximum 99\%) compared with isolate TM (maximum $88 \%$ ). Burials of sclerotia from May onward showed a decline in final percentage germination at both field sites, and those made from June onward resulted in little or no germination, as shown for 2003 and 2004 (Table 3). This typical pattern of germination is illustrated for the Cheshire field site in 2004, plotted with rainfall, mean soil temperature, and water potential data (Fig. 1). There was some variation between the theta probe values for soil water content (data not shown). In this year, as in some other years, it was noted that large decreases in soil water potential often coincided with periods of time where no new apothecia were produced (seen as flat areas on the cumulative germination curves). There was no evidence of degradation of sclerotia buried in the mesh bags in any of the burials in any year after 6 weeks.

A predictive model for germination of sclerotia. The first model optimization procedure was modified as follows in order to make the fitting process converge. The conditioning rate was set to 0 for temperatures $\geq 20^{\circ} \mathrm{C}$ for isolate 13 and $>20^{\circ} \mathrm{C}$ for isolate TM. Germination rate was set to 0 for temperatures $>25^{\circ} \mathrm{C}$ for both $S$. sclerotiorum isolates. The first optimization procedure indicated that the temperature-dependent rates for conditioning and germination of both isolates could be described by a modified exponential curve (equation 2) and an Arrhenius curve (equation 3), respectively (Fig. 2). Parameters for these curves estimated during the second optimization procedure are shown in Table 4. For isolate 13, the model-fitting process showed that it was not possible to find an optimum value for parameter $b$ (equation 2) but suggested it was $>10$. Therefore, $b$ was set to an arbitrary value of 1,000. In practice, any value between 10 and 5,000 allowed the other parameters to be optimized and gave estimates of

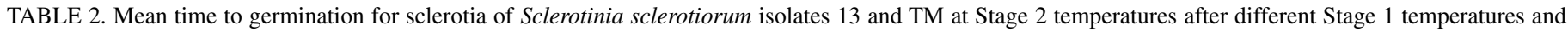
durations (Experiments 2 and 3 )

\begin{tabular}{|c|c|c|c|c|c|c|c|c|c|}
\hline \multicolumn{5}{|c|}{ Experiment 2a } & \multicolumn{5}{|c|}{ Experiment 3} \\
\hline $\begin{array}{l}\text { S1 } \\
\text { temperature }\end{array}$ & $\begin{array}{c}\mathrm{S} 1 \\
\text { duration }^{\mathrm{b}}\end{array}$ & $\begin{array}{c}\mathrm{S} 2 \\
\text { temperature }^{\mathrm{c}}\end{array}$ & Mean time $13^{\mathrm{d}}$ & Mean time $\mathrm{TM}^{\mathrm{d}}$ & $\begin{array}{c}\mathrm{S} 1 \\
\text { temperature }^{\mathrm{a}}\end{array}$ & $\begin{array}{c}\mathrm{S} 1 \\
\text { duration }^{\mathrm{b}}\end{array}$ & $\begin{array}{c}\mathrm{S} 2 \\
\text { temperature }^{\mathrm{c}}\end{array}$ & Mean time $13^{\mathrm{d}}$ & Mean time $\mathrm{TM}^{\mathrm{d}}$ \\
\hline 4 & 30 & 15 & $57.6(4.5)$ & $94.9(9.2)$ & 4 & 0 & 10 &.$^{\mathrm{e}}$ & $\cdots$ \\
\hline 7 & 30 & 15 & $50.9(3.8)$ & $87.7(7.8)$ & 4 & 0 & 13 & $175.0(13.3)$ & $\ldots$ \\
\hline 10 & 30 & 15 & $56.1(5.7)$ & $105.4(12.0)$ & 4 & 0 & 15 & $75.1(4.4)$ & 241.8 (371.7) \\
\hline 13 & 30 & 15 & $51.0(4.2)$ & $156.5(\ldots)$ & 4 & 0 & 18 & $82.6(1.4)$ & $\ldots$ \\
\hline 15 & 30 & 15 & $62.6(4.6)$ & $\ldots$ & 4 & 0 & 25 & $\ldots$ & $\ldots$ \\
\hline 20 & 30 & 15 & $87.7(4.6)$ & $159.6(44.4)$ & 4 & 15 & 10 & $76.8(6.4)$ & $102.2(2.9)$ \\
\hline 4 & 50 & 15 & $41.6(2.4)$ & $57.4(3.4)$ & 4 & 15 & 13 & $65.1(5.2)$ & $90.9(3.8)$ \\
\hline 7 & 50 & 15 & $40.6(3.9)$ & $89.8(17.7)$ & 4 & 15 & 15 & $40.7(1.1)$ & $71.9(13.0)$ \\
\hline 10 & 50 & 15 & $43.5(4.2)$ & $84.5(5.3)$ & 4 & 15 & 18 & $41.8(3.8)$ & $57.0(5.5)$ \\
\hline 13 & 50 & 15 & $44.1(4.5)$ & $137.7(28.0)$ & 4 & 15 & 25 & $\ldots$ & $\ldots$ \\
\hline 15 & 50 & 15 & $46.8(4.4)$ & $\ldots$ & 4 & 30 & 10 & $100.9(6.4)$ & $124.2(6.5)$ \\
\hline 20 & 50 & 15 & $67.1(3.0)$ & $158.7(0.99)$ & 4 & 30 & 13 & $69.7(5.2)$ & $90.8(6.0)$ \\
\hline 4 & 77 & 15 & $48.1(7.0)$ & $47.7(2.2)$ & 4 & 30 & 15 & $38.5(1.1)$ & $55.2(1.8)$ \\
\hline 7 & 77 & 15 & 38.7 (8.6) & $58.3(3.7)$ & 4 & 30 & 18 & $44.5(3.8)$ & $43.6(2.0)$ \\
\hline 10 & 77 & 15 & $51.5(7.8)$ & $66.5(2.3)$ & 4 & 30 & 25 & $\ldots$ & $\ldots$ \\
\hline 13 & 77 & 15 & $46.0(9.1)$ & $80.4(2.8)$ & 4 & 50 & 10 & $86.3(5.1)$ & $108.7(4.2)$ \\
\hline 15 & 77 & 15 & $40.3(13.0)$ & $110.4(7.4)$ & 4 & 50 & 13 & $59.7(2.7)$ & $90.47(6.6)$ \\
\hline 20 & 77 & 15 & $77.2(6.5)$ & $111.5(1.1)$ & 4 & 50 & 15 & 41.7 (1.5) & $51.5(3.5)$ \\
\hline 4 & 100 & 15 & $40.3(3.3)$ & $52.9(3.3)$ & 4 & 50 & 18 & $45.5(1.1)$ & $43.7(2.0)$ \\
\hline 7 & 100 & 15 & $37.3(7.4)$ & $71.5(5.6)$ & 4 & 50 & 25 & $40.0(4.3)$ & $\ldots$ \\
\hline 10 & 100 & 15 & $36.1(9.5)$ & $58.6(3.8)$ & 4 & 75 & 10 & $79.3(3.6)$ & $120.1(2.7)$ \\
\hline 13 & 100 & 15 & $\ldots$ & $87.4(6.4)$ & 4 & 75 & 13 & $46.9(2.6)$ & 79.7 (2.9) \\
\hline 15 & 100 & 15 & $\ldots$ & $64.4(2.8)$ & 4 & 75 & 15 & $34.1(2.7)$ & $54.8(2.0)$ \\
\hline \multirow[t]{7}{*}{20} & 100 & 15 & $69.0(6.4)$ & $92.4(1.7)$ & 4 & 75 & 18 & $31.6(2.0)$ & $58.3(2.4)$ \\
\hline & & & & & 4 & 75 & 25 & $27.8(3.8)$ & $\ldots$ \\
\hline & & & & & 4 & 100 & 10 & $67.3(3.6)$ & $112.7(5.3)$ \\
\hline & & & & & 4 & 100 & 13 & $46.4(3.0)$ & $75.3(4.1)$ \\
\hline & & & & & 4 & 100 & 15 & $28.0(2.3)$ & $50.1(1.8)$ \\
\hline & & & & & 4 & 100 & 18 & $26.9(1.2)$ & $47.0(1.1)$ \\
\hline & & & & & 4 & 100 & 25 & $22.1(2.5)$ & $48.0(0.0)$ \\
\hline
\end{tabular}

a Stage 1 temperature $\left({ }^{\circ} \mathrm{C}\right)$.

b Stage 1 duration (days).

c Stage 2 temperature $\left({ }^{\circ} \mathrm{C}\right)$.

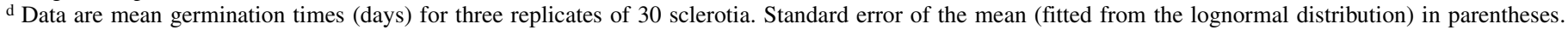

High or missing standard errors are due to low final percentage germination.

e Dots represent missing values. 
about 30 days for duration of conditioning at temperatures of $10^{\circ} \mathrm{C}$ and above. This estimation problem arose because there was insufficient data with $<30$ days Stage 1 duration at temperatures $<10^{\circ} \mathrm{C}$.

The relationship between temperature and conditioning (Fig. 2) showed that this process is rapid at low temperatures of 5 to $7^{\circ} \mathrm{C}$, with rates quickly decreasing as temperature increases. For instance, transforming the rates in Fig. 2 to mean times to germination, S. sclerotiorum isolate 13 took 2 days to condition at $5^{\circ} \mathrm{C}$ and isolate TM took 6 days. At $15^{\circ} \mathrm{C}$, isolate 13 took 30 days and TM took 80 days. Hence, the two $S$. sclerotiorum isolates had different responses, with isolate 13 conditioning more rapidly than isolate TM. The relationship between germination and temperature showed that this phase was fastest at 18 to $20^{\circ} \mathrm{C}$. Germination took 240 days for isolate 13 at $5^{\circ} \mathrm{C}$ and 271 days for isolate TM, whereas at $20^{\circ} \mathrm{C}$, isolate 13 took 33 days and isolate TM took 52 days. Again, therefore, the two isolates had a different response to temperature, with isolate 13 consistently faster than TM.

The fit of the germination model provided a good explanation of the germination data in all experiments (Fig. 3). For combined data from Experiments 2 and 3 (sclerotia conditioned in soil), the model accounted for $75 \%$ of the variation in the observed data for isolate 13 and $85 \%$ of the variation for isolate TM.

Testing the model for germination of sclerotia using field data. Sclerotia which were buried in the field in 2000, 2001, 2003 , and 2004 had been conditioned for 28 days in flasks at $4^{\circ} \mathrm{C}$. As stated previously, it was necessary to determine the degree of conditioning this treatment represented for each S. sclerotiorum isolate before the germination model could be applied to the field data. The relationship between temperature and germination (equation 3) was used to calculate the fraction of germination achieved in Stage 2, and then equation 4 was used to estimate conditioning and germination times for sclerotia in the flasks. Data for sclerotia incubated at $4^{\circ} \mathrm{C}$ for $>101$ days in flasks were omitted from the regression calculation (equation 4) because the plateau in mean germination times indicated that there was no further benefit in increasing time at Stage 1 beyond approximately 100 days (Table 1$)$. Estimates for conditioning time $\left(c_{4}\right.$, equation 4) in flasks were 62 and 25 days, respectively, for isolates 13 and TM, and 86 and 136 days for germination ( $g_{4}$, equation 4$)$. In practice however, only a fraction of germination took place in the flasks (as germination times in Stage 2 for $>100$ days in Stage 1 did not decrease) and this was estimated as 0.6 (where $1.0=$ germination occurs). When conditioning and germination rates in flasks were used in conjunction with equation 3 , the calculated mean times to germination were a good fit to the observed data in Experiment 1 (Fig. 3), accounting for 82 and $88 \%$ of the variation for isolates 13 and TM, respectively. The fraction of conditioning occurring for sclerotia incubated for 28 days in flasks at $4^{\circ} \mathrm{C}$ before burial in the field was therefore $28 / 62=0.45$ for isolate 13 and $28 / 25=1.12$ for isolate TM. Hence sclerotia of isolate 13 were partially conditioned when buried in the field, and TM sclerotia were fully conditioned. For all years except 2005 (when unconditioned sclerotia were buried), a starting cumulative conditioning rate of 0.45 was therefore used for isolate 13 when applying the model to the field data, whereas for isolate TM, the conditioning part of the model was not run at all. As no germination of $S$. sclerotiorum sclerotia occurred above $25^{\circ} \mathrm{C}$ in previous experiments (7), and conditioning appeared to be negligible above $20^{\circ} \mathrm{C}$ in Experiments 2 and 3, these values were used as upper temperature thresholds for germination and conditioning respectively.

TABLE 3. Final percent germination, and both the observed and predicted times of germination of sclerotia of Sclerotinia sclerotiorum isolate 13 (Cheshire) and isolate TM (Norfolk) in 2003 and 2004

\begin{tabular}{|c|c|c|c|c|c|c|c|c|c|}
\hline \multicolumn{5}{|c|}{ Isolate 13} & \multicolumn{5}{|c|}{ Isolate TM } \\
\hline Burial date & WP threshold ${ }^{\mathrm{a}}$ & Final germ. ${ }^{\mathrm{b}}$ & Obs. $\mathrm{T} 50^{\mathrm{c}}$ & Pred. T50 & Burial date & WP threshold ${ }^{\mathrm{a}}$ & Final germ. ${ }^{b}$ & Obs. T50 & Pred. T50 ${ }^{\mathrm{d}}$ \\
\hline $23 / 12 / 02$ & -6.50 & 94.0 & 146.3 & 149.0 & $18 / 12 / 02$ & -4.25 & 88.3 & 182.8 & 192.7 \\
\hline $04 / 03 / 03$ & -6.50 & 93.3 & 117.7 & 88.4 & 03/03/03 & -4.25 & 1.0 & $\ldots e^{e}$ & 150.3 \\
\hline $17 / 03 / 03$ & -6.50 & 89.5 & 107.6 & 78.1 & $17 / 03 / 03$ & -4.25 & 65.0 & 145.2 & 146.4 \\
\hline $31 / 03 / 03$ & -6.50 & 99.5 & 93.7 & 69.5 & $31 / 03 / 03$ & -4.25 & 63.3 & 161.4 & 173.9 \\
\hline $14 / 04 / 03$ & -6.50 & 97.0 & 103.8 & 83.0 & $15 / 04 / 03$ & -4.25 & 25.8 & $\ldots$ & 160.4 \\
\hline $28 / 04 / 03$ & -6.50 & 96.8 & 91.6 & 147.1 & $29 / 04 / 03$ & -4.25 & 22.3 & $\ldots$ & 147.0 \\
\hline $12 / 05 / 03$ & -6.50 & 84.0 & 118.0 & 152.9 & $15 / 05 / 03$ & -4.25 & 0.0 & $\ldots$ & 163.6 \\
\hline $27 / 05 / 03$ & -6.50 & 55.0 & 141.0 & $\ldots$ & $28 / 05 / 03$ & -4.25 & 0.0 & $\ldots$ & $\ldots$ \\
\hline $10 / 06 / 03$ & -6.50 & 0.0 & $\ldots$ & $\ldots$ & $09 / 06 / 03$ & -4.25 & 0.0 & $\ldots$ & $\ldots$ \\
\hline $23 / 06 / 03$ & -6.50 & 0.0 & $\ldots$ & $\ldots$ & $24 / 06 / 03$ & -4.25 & 0.0 & $\ldots$ & $\ldots$ \\
\hline 08/07/03 & -6.50 & 0.3 & $\ldots$ & $\ldots$ & 07/07/03 & -4.25 & 0.0 & $\ldots$ & $\ldots$ \\
\hline $21 / 07 / 03$ & -6.50 & 1.3 & $\ldots$ & $\ldots$ & $23 / 07 / 03$ & -4.25 & 0.0 & $\ldots$ & $\ldots$ \\
\hline $04 / 08 / 03$ & -6.50 & 0.3 & $\ldots$ & $\ldots$ & 04/08/03 & -4.25 & 0.0 & $\ldots$ & $\ldots$ \\
\hline $17 / 12 / 03$ & -8.00 & 84.3 & 145.3 & 149.1 & $17 / 12 / 03$ & -4.00 & 74.3 & 214.5 & 212.5 \\
\hline $21 / 01 / 04$ & -8.00 & 87.3 & 152.8 & 150.9 & $14 / 01 / 04$ & -4.00 & 38.8 & $\ldots$ & 209.3 \\
\hline $12 / 02 / 04$ & -8.00 & 58.3 & 167.9 & 138.3 & $09 / 02 / 04$ & -4.00 & 45.3 & $\ldots$ & 189.3 \\
\hline $02 / 03 / 04$ & -8.00 & 91.0 & 106.2 & 132.9 & $03 / 03 / 04$ & -4.00 & 74.8 & 170.4 & 171.6 \\
\hline $17 / 03 / 04$ & -8.00 & 78.0 & 105.1 & 122.4 & $15 / 03 / 04$ & -4.00 & 52.5 & 199.1 & 162.9 \\
\hline $29 / 03 / 04$ & -8.00 & 86.8 & 94.0 & 118.3 & $29 / 03 / 04$ & -4.00 & 78.8 & 150.9 & 155.1 \\
\hline $13 / 04 / 04$ & -8.00 & 76.0 & 108.7 & 122.2 & $13 / 04 / 04$ & -4.00 & 38.0 & $\ldots$ & 153.1 \\
\hline $28 / 04 / 04$ & -8.00 & 75.8 & 117.6 & 115.8 & $26 / 04 / 04$ & -4.00 & 11.0 & $\ldots$ & 152.6 \\
\hline $11 / 05 / 04$ & -8.00 & 63.3 & 131.8 & 125.3 & $10 / 05 / 04$ & -4.00 & 7.5 & $\ldots$ & 149.6 \\
\hline $25 / 05 / 04$ & -8.00 & 43.8 & $\ldots$ & 126.1 & $24 / 05 / 04$ & -4.00 & 0.5 & $\ldots$ & 143.8 \\
\hline 09/06/04 & -8.00 & 44.3 & $\ldots$ & 115.1 & 07/06/04 & -4.00 & 0.5 & $\ldots$ & $\ldots$ \\
\hline $24 / 06 / 04$ & -8.00 & 19.8 & $\ldots$ & 104.9 & $21 / 06 / 04$ & -4.00 & 0.0 & $\ldots$ & $\ldots$ \\
\hline $07 / 07 / 04$ & -8.00 & 14.0 & $\ldots$ & $\ldots$ & 05/07/04 & -4.00 & 0.0 & $\ldots$ & $\ldots$ \\
\hline $22 / 07 / 04$ & -8.00 & 1.8 & $\ldots$ & $\ldots$ & $19 / 07 / 04$ & -4.00 & 0.0 & $\ldots$ & $\ldots$ \\
\hline $02 / 08 / 04$ & -8.00 & 1.3 & $\ldots$ & $\ldots$ & $02 / 08 / 04$ & -4.00 & 0.0 & $\ldots$ & $\ldots$ \\
\hline 08/09/04 & -8.00 & 0.0 & $\ldots$ & $\ldots$ & $15 / 09 / 04$ & -4.00 & 0.0 & $\ldots$ & $\ldots$ \\
\hline $05 / 10 / 04$ & -8.00 & 0.0 & $\ldots$ & $\ldots$ & $06 / 10 / 04$ & -4.00 & 0.0 & $\ldots$ & $\ldots$ \\
\hline
\end{tabular}

a Water potential threshold $(\mathrm{kPa})$.

${ }^{\mathrm{b}}$ Final observed percent germination.

c Observed time to $50 \%$ germination (days).

d Predicted time to $50 \%$ germination (days).

e Dots indicate no germination or prediction. 
For the water potential threshold, a range between $-100 \mathrm{kPa}$ and $-300 \mathrm{kPa}$ as suggested by results from Clarkson et al. (7) was initially applied. However, it was clear that this threshold range had little or no effect on the simulated germination curves, as the soil water potential in the field recorded by the logger rarely fell within this range. Thresholds were therefore tested in the range 0 (no threshold) to $-20 \mathrm{kPa}$ in $0.25 \mathrm{kPa}$ steps. Predicted germination times were found to be optimum when water potential thresholds were set between -6.5 and $-12.25 \mathrm{kPa}$ for $S$. sclerotiorum isolate 13 (Cheshire field site) and between -4.0 and $-4.25 \mathrm{kPa}$ for isolate TM (Norfolk field site). Small changes in the threshold value occasionally had a large effect on predictions. However, overall, the model successfully reproduced the observed pattern of germination from sclerotia buried at different times of year at Cheshire and Norfolk, predicting both germination of the earlier burials and nongermination of the later burials. This was evident from the close association of the simulation curves for germination produced by the model and the cumulative germination curves observed for the buried sclerotia in all years, examples of which are shown in Fig. 4 for selected burials in 2004. If the initial conditioning values for each $S$. sclerotiorum isolate were not applied before the germination model was applied, and given a starting value of 0 for 13 and TM (unconditioned) or 1 (fully conditioned) for isolate 13 , then predictions of germination were less accurate, suggesting that the estimates of conditioning in the flasks for each isolate were correct.
Although the pattern of germination could be simulated by the germination model, the accuracy of predicting the exact time after burial that T10 and T50 would occur for the buried sclerotia in the field experiments varied, but was generally better for burials early in the year. However, approximately $80 \%$ of the 64 burials at each site over 5 years were correctly predicted for germination or nongermination, which was significantly better than would be expected by chance $(P<0.001)$ as determined by the chi-square test summarized in Table 5.

\section{DISCUSSION}

This is the first study to present a model for production of apothecia by $S$. sclerotiorum sclerotia based on mathematical relationships between temperature and rates of conditioning and germination.

The conditioning part of the model indicated that temperatures below $10^{\circ} \mathrm{C}$ are optimum for this process and that at $5^{\circ} \mathrm{C}$, conditioning can be completed in just a few days. In contrast, the germination part of the model suggested an optimum of 18 to $20^{\circ} \mathrm{C}$, with the process completed in approximately 30 to 50 days, depending on the isolate. Similarly, Phillips (19) showed that conditioning $S$. sclerotiorum sclerotia for increasing durations at $5^{\circ} \mathrm{C}$ resulted in faster subsequent germination at $18^{\circ} \mathrm{C}$. A relationship between duration of chilling time and germination rate of pseudosclerotia of Monilinia vaccinii-corymbosi, which is related to $S$.
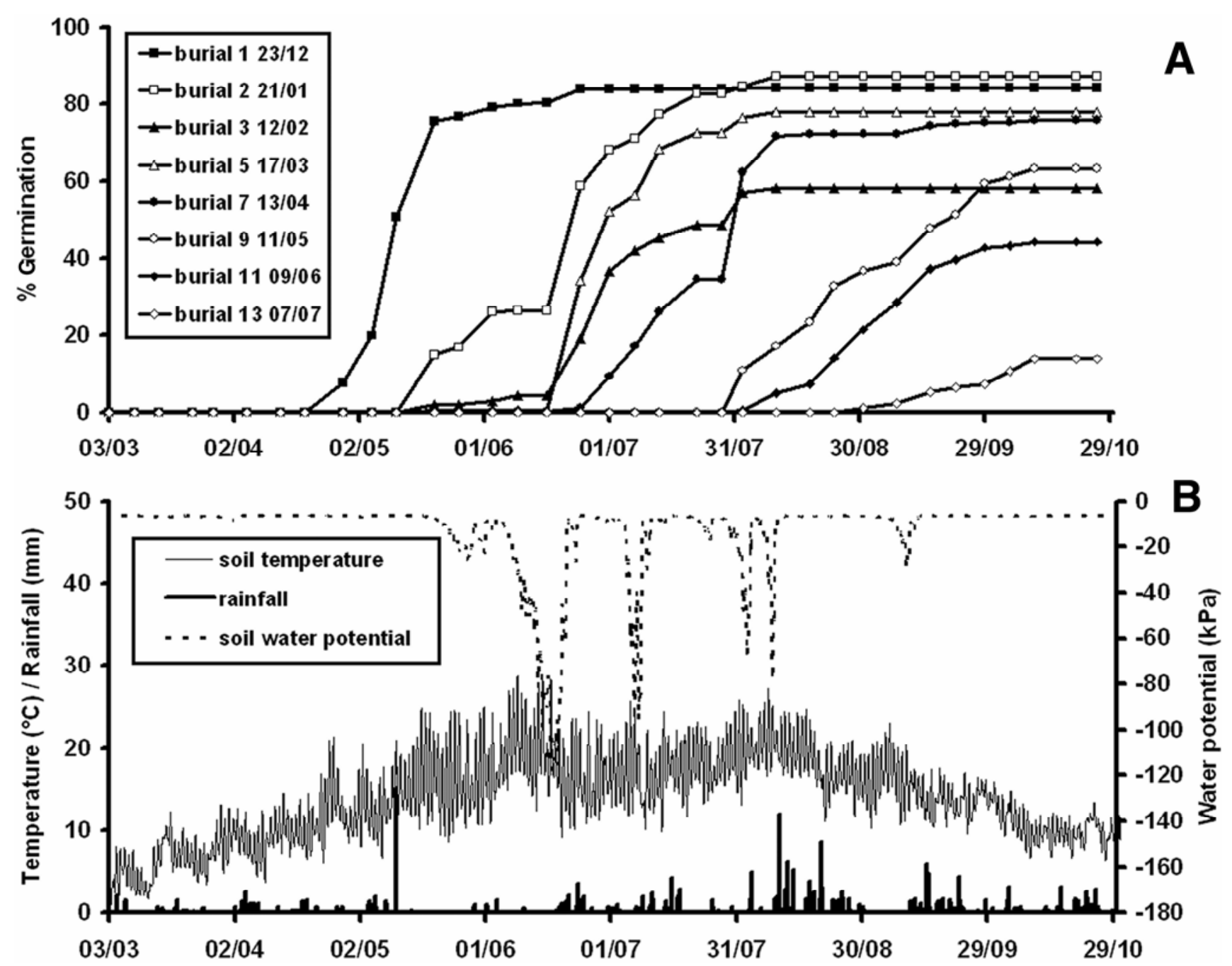

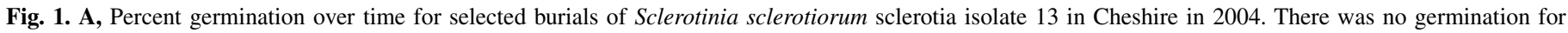

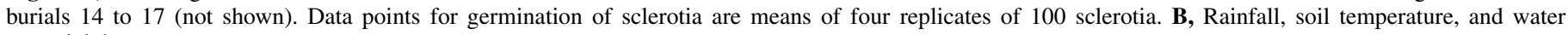
potential data. 
sclerotiorum, was also found by Scherm et al. (22), while Dillard et al. (9) showed that conditioning $S$. sclerotiorum sclerotia for 4 weeks between 4 and $16^{\circ} \mathrm{C}$ resulted in good germination at $20^{\circ} \mathrm{C}$ after 8 weeks, compared with a conditioning temperature of $24^{\circ} \mathrm{C}$.
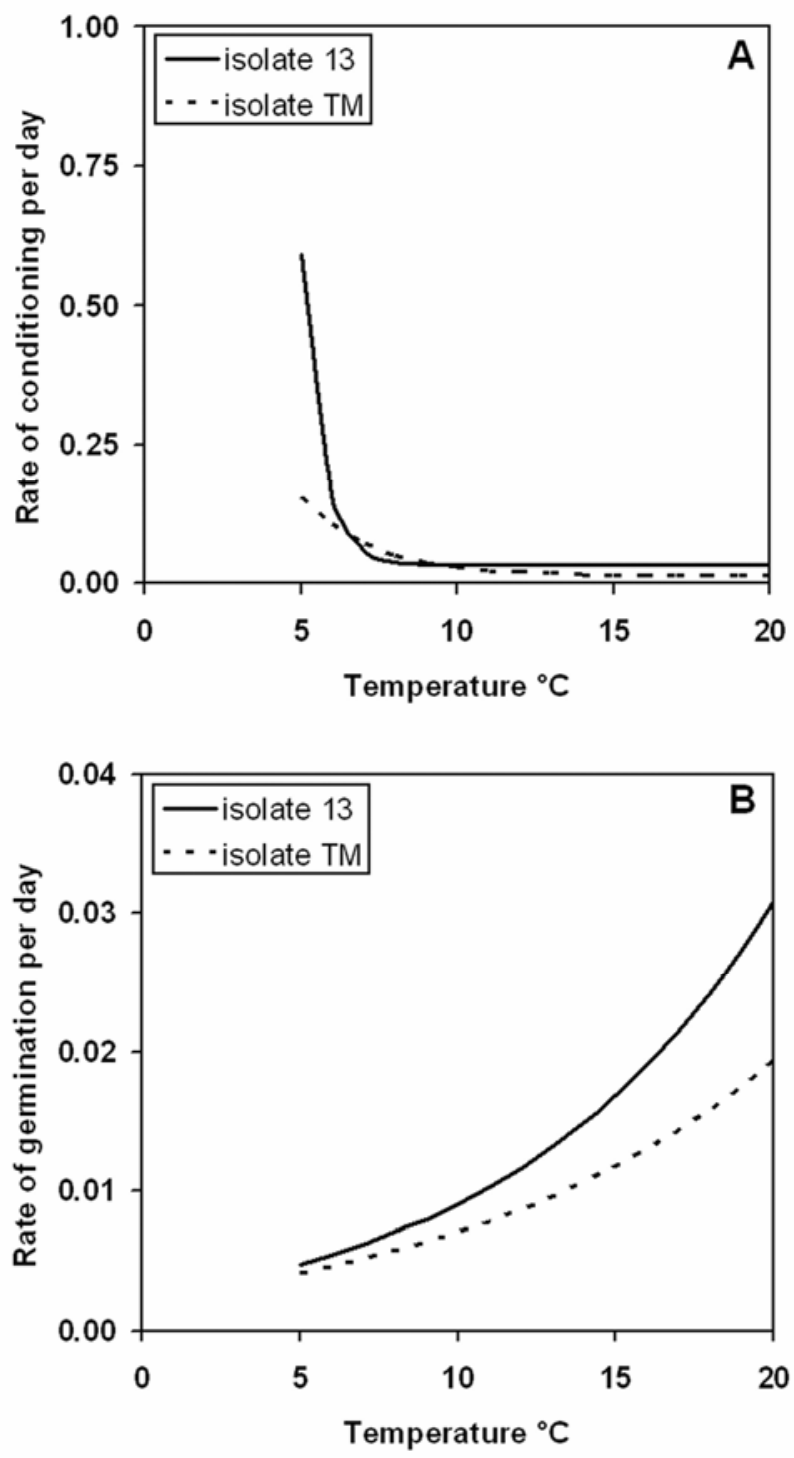

Fig. 2. Fitted curves for $\mathbf{A}$, conditioning rate and $\mathbf{B}$, germination rate of Sclerotinia sclerotiorum isolates 13 and TM with temperature.

TABLE 4. Parameter values for estimating rates (per day) of conditioning and germination model for carpogenic germination model for Sclerotinia sclerotiorum sclerotia

\begin{tabular}{llllll}
\hline & \multicolumn{3}{c}{ Isolate 13 } & & \multicolumn{2}{c}{ Isolate TM } \\
\cline { 2 - 3 } \cline { 6 - 6 } Parameter & $\begin{array}{c}\text { Parameter } \\
\text { value }\end{array}$ & $\begin{array}{c}\text { Standard } \\
\text { error }\end{array}$ & & $\begin{array}{c}\text { Parameter } \\
\text { value }\end{array}$ & $\begin{array}{c}\text { Standard } \\
\text { error }\end{array}$ \\
\hline $\begin{array}{l}\text { Conditioning function } \\
\text { (equation 2) }\end{array}$ & & & & & \\
$a$ & 0.03273 & 0.00395 & & 0.01056 & 0.001 \\
$b$ & 1,000 & $\ldots^{\mathrm{a}}$ & & 1.28 & 1.61 \\
$k$ & 1.498 & 0.398 & & 0.435 & 0.118 \\
$\begin{array}{l}\text { Germination function } \\
\text { (equation 3) }\end{array}$ & & & & & \\
$d_{0}$ & 31.12 & 4.36 & & 24.8 & 3.38 \\
$d_{1}$ & $-10,138$ & 1,236 & & $-8,422$ & 961 \\
\hline
\end{tabular}

a Dots indicate missing standard error as parameter not estimated.
The ability to assess the effect of temperature separately on conditioning and on germination was a key factor in deriving a predictive model for production of apothecia. Other workers who have investigated temperature effects on carpogenic germination sometimes precondition sclerotia (25) and sometimes do not (12), which may to some extent explain the wide range of optimum temperatures reported for this process (20). Our model suggests that if a long, cold period is applied, sclerotia will have completed conditioning and started the germination process, and hence, apothecia appear to be produced very rapidly when transferred to higher temperatures. However, if no conditioning period is applied, then the need for cold conditions before rapid germination can take place may result in lower temperatures appearing to be optimum. Furthermore, the long timescale for germination of $S$. sclerotiorum sclerotia in sub-optimal temperature regimes, means that studies carried out over short periods of time may miss important effects. It is clear that there is a delicate balance between the conditioning and germination processes because of their very different temperature optima. According to our germination model for isolate 13 , the total time taken for sclerotia to condition and germinate at a constant $5^{\circ} \mathrm{C}$ is 212 days compared to 72 days at $18^{\circ} \mathrm{C}$. However, if sclerotia are effectively conditioned in a day at $5^{\circ} \mathrm{C}$ and transferred to $18^{\circ} \mathrm{C}$, the total time taken is only approximately 40 days.

S. sclerotiorum isolates 13 and TM clearly differed in their response to temperature for both conditioning and germination processes, and this illustrates the importance of considering more than one isolate in modeling studies. Dillard et al. (9) also found variation in optimum conditioning temperature for 24 isolates of S. sclerotiorum, and Huang \& Kozub (13) showed that 20 isolates of different geographic origin had different temperature requirements for carpogenic germination. These results suggest that perhaps not all $S$. sclerotiorum isolates require a cold period to condition and that there may be local adaptation where the process takes place at higher temperatures. Genetic variability in $S$. sclerotiorum is well documented through mycelial compatibility tests, DNA fingerprinting, microsatellite markers, and gene sequencing, with evidence for dominant clonal populations as well as for outcrossing and recombination events occurring in the field $(3,8,14,23)$. It has also been shown that $S$. sclerotiorum isolates may be grouped into subtropical, temperate, wild, and more recently evolved temperate subtropical populations (6), suggesting that

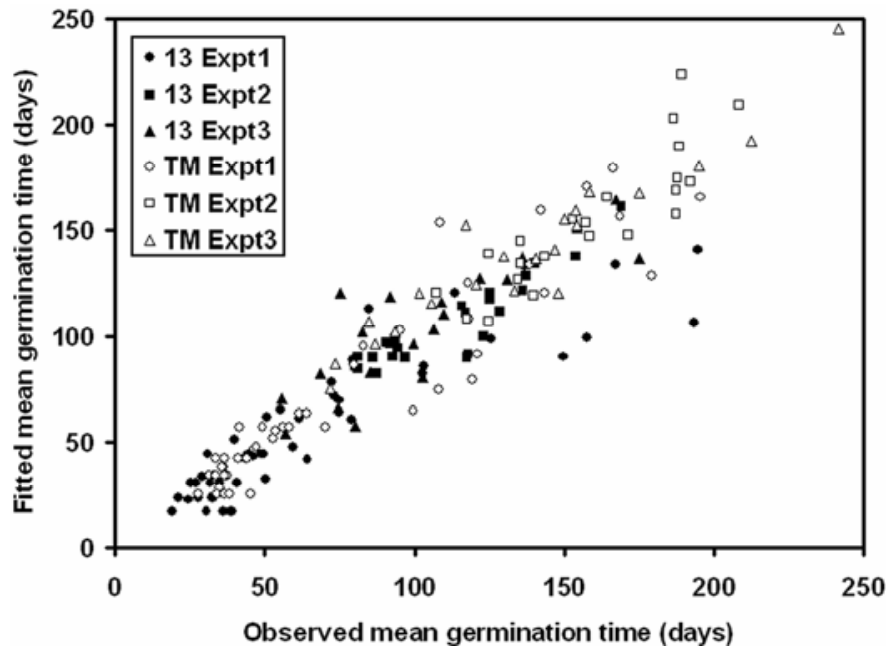

Fig. 3. Observed and fitted overall mean germination times (days) for Sclerotinia sclerotiorum isolates 13 and TM in Experiments 1, 2, and 3 (Stage $1+$ Stage 2). Fitted germination times were calculated using the carpogenic germination model, which combines temperature-dependent rates for conditioning and germination (equations 2 and 3 ). $\mathrm{R}^{2}=0.89$ over all experiments. 
environmental and ecological conditions are important factors in local adaptation.

This work also showed that conditioning rates for sclerotia kept in flasks containing wheat grain were different from those for sclerotia buried in soil. A similar phenomenon was also observed by Phillips (19) when comparing conditioning in soil with that in vermiculite. The inability of sclerotia to germinate in flasks even after extended periods of time may have been due to a lack of oxygen, which has been proposed as a mechanism for why sclerotia buried more than approximately $7 \mathrm{~cm}$ deep do not germinate in soil (20).

A consistent pattern of germination of $S$. sclerotiorum sclerotia was observed in the field as first described by Clarkson et al. (7). Sclerotia buried from January to April germinated, but those
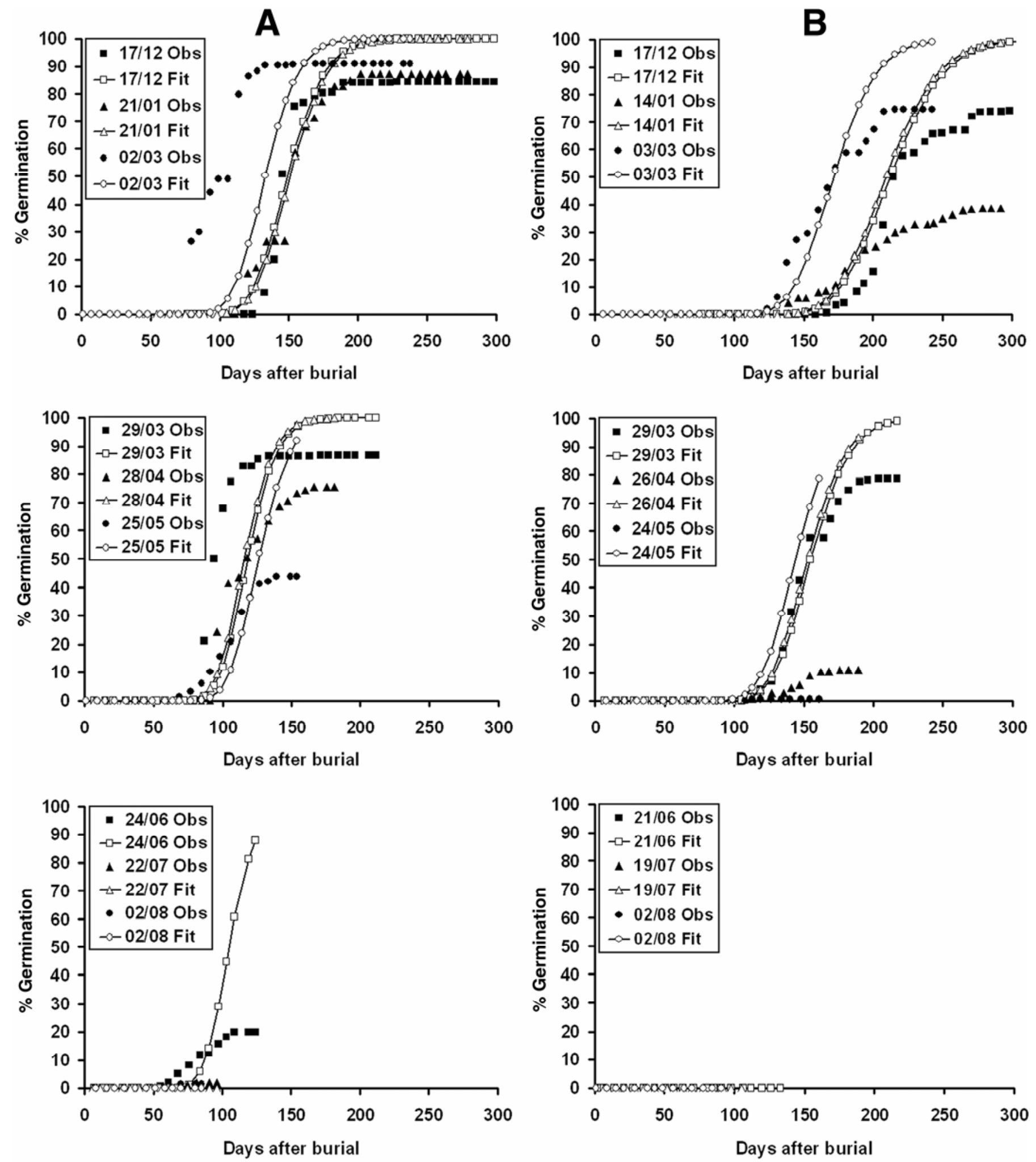

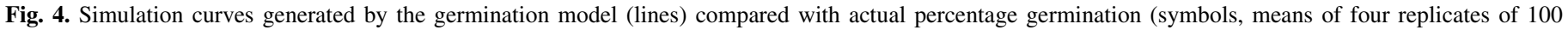

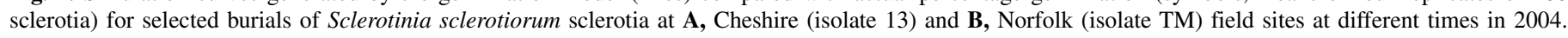
Water potential thresholds applied were $-8.0 \mathrm{kPa}$ for isolate 13 and $-4.0 \mathrm{kPa}$ for isolate TM. 
buried from June onward showed little or no germination in the same year. This pattern was successfully reproduced by the germination model, suggesting that our approach has addressed the key factors involved. As sclerotia of isolate TM were fully conditioned when buried in the field, the decline in germination of sclerotia buried later in the year can be attributed to increasing periods of time where soil temperature was greater than the $25^{\circ} \mathrm{C}$ threshold and soil water potential was limiting. The same is true for isolate 13 , but as sclerotia were partially conditioned when buried for this isolate, germination was further constrained in later burials by the lack of cold temperatures required for completion of this phase.

The accuracy of the germination model in predicting the time of carpogenic germination was variable, and for some burials, there was up to 30 days' difference in observed mean germination times. The model, however, was found to be very sensitive to the water potential thresholds imposed between -4.0 and $-12.25 \mathrm{kPa}$, and this is one of the main factors affecting prediction of germination time. Furthermore, unlike the upper temperature thresholds imposed on conditioning and germination $\left(20\right.$ and $25^{\circ} \mathrm{C}$ respecttively), the water potential thresholds did not agree with results from the laboratory experiments or elsewhere where a value of approximately $-100 \mathrm{kPa}$ might be appropriate. This highlights the problem in measuring soil water potential in the field and relating it to actual water available to the sclerotia. In this study, theta probes were used to measure soil water content, which was then converted to soil water potential. The probes measure soil water content over a depth of $6 \mathrm{~cm}$, which is likely to give a higher value than that experienced by the sclerotia buried $1 \mathrm{~cm}$ below the soil surface. This might explain why the recorded soil water potential value rarely dropped below $-100 \mathrm{kPa}$. The problem was also compounded by the fact that the measurements from the five theta probes used at each field site were also variable even though the probes were in close proximity to each other. Therefore, although a threshold water potential is warranted, it remains a challenge to determine an accurate and realistic threshold for a range of soil types for use in a carpogenic germination model.

There are clearly some important issues to consider before using the carpogenic germination model in a practical situation to forecast Sclerotinia disease. Firstly, in practice, the aim would be to start the model when tillage operations bring sclerotia to the surface where they can germinate. In a typical field situation it could be assumed that these sclerotia would be fully conditioned, having survived at least one winter period. Therefore, although we needed to understand the process of conditioning to achieve the aims of this study, this part of the model would not be required in practice. Secondly, the problems in measuring soil water

TABLE 5. Number of occasions on which correct or incorrect predictions of 10 or $50 \%$ germination of sclerotia were made by the germination model for sclerotia of Sclerotinia sclerotiorum isolates 13 and TM buried at Cheshire and Norfolk

\begin{tabular}{lccccc}
\hline & \multicolumn{2}{c}{ Cheshire } & & \multicolumn{2}{c}{ Norfolk } \\
\cline { 2 - 3 } \cline { 5 - 6 } $\begin{array}{c}\text { Predicted or } \\
\text { Observed }^{\mathrm{a}}\end{array}$ & $\begin{array}{c}10 \% \\
\text { germination }\end{array}$ & $\begin{array}{c}50 \% \\
\text { germination }\end{array}$ & $\begin{array}{c}10 \% \\
\text { germination }\end{array}$ & $\begin{array}{c}50 \% \\
\text { germination }\end{array}$ \\
\hline $\begin{array}{c}\text { Predicted and } \\
\text { observed }^{\mathrm{a}}\end{array}$ & 33 & 28 & & 32 & 35 \\
$\begin{array}{c}\text { Not predicted, } \\
\text { not observed }\end{array}$ & 20 & 24 & & 24 & 9 \\
$\begin{array}{c}\text { Predicted, not } \\
\text { observed }\end{array}$ & 3 & 3 & & 4 & 20 \\
$\begin{array}{c}\text { Not predicted, } \\
\text { observed }\end{array}$ & 8 & 4 & & 4 & 0 \\
$\begin{array}{c}\text { Total burials } \\
\text { Significance } \\
\left(\chi^{2} \text { test }\right)\end{array}$ & 64 & 64 & & 64 & 64 \\
\hline
\end{tabular}

${ }^{\text {a }}$ Correct prediction.

${ }^{\mathrm{b}}$ Incorrect prediction. potential accurately and reliably and the general inaccessibility of and problems in obtaining these data may mean that another approach to water availability is required based on rainfall. This is a major challenge in itself, but there has been some progress in modeling soil water potential from rainfall and soil physical data (26).

The differential response to temperature of the two $S$. sclerotiorum isolates used in this study is also problematic. Clearly it is not practical to estimate different model parameters for dominant isolates from different areas, especially as, although populations of $S$. sclerotiorum may be predominantly clonal, the same range of clones may not always be present from year to year (11). To address this, more information is required on the variability in temperature response of isolates in the United Kingdom and only then can a generic model be considered. It may be that the diversity is such that very accurate prediction of germination and production of apothecia is not possible. In this case, more general risk periods might be determined based on information from this study and simulations with historical weather data. For instance, for lettuce, where multiple crops are grown in the field in quick succession from April to October, it may be possible to identify periods during the season when apothecia and ascospores are not present, and hence avoid unnecessary fungicide applications. Finally, identifying times when ascospores are present does not necessarily mean that infection of plants will occur. Further modeling studies to understand conditions required for infection are also in progress based on previous work (27) which, when combined with a simplified carpogenic germination model, may allow effective prediction of Sclerotinia disease in field lettuce.

\section{ACKNOWLEDGMENTS}

We thank R. Pearce for technical support. We thank the Department for Environment, Food, and Rural Affairs, London, for financial support through project $\mathrm{HH} 3215 \mathrm{TFV}$.

\section{LITERATURE CITED}

1. Abawi, G. S., and Grogan, R. G. 1975. Source of primary inoculum and effects of temperature and moisture on infection of beans by Whetzelinia sclerotiorum. Phytopathology 65:300-309.

2. Allen, P. 2003. When and how many? Hydrothermal models and the prediction of seed germination. New Phytol.158:1-3.

3. Atallah, Z. K., Larget, B., Chen, X., and Johnson, D. A. 2004. High genetic diversity, phenotypic uniformity, and evidence of outcrossing in Sclerotinia sclerotiorum in the Columbia basin of Washington state. Phytopathology 94:737-742.

4. Ben-Yephet, Y., Genizi, A., and Siti, E. 1993. Sclerotial survival and apothecial production by Sclerotinia sclerotiorum following outbreaks of lettuce drop. Phytopathology 83:509-513.

5. Boland, G. J., and Hall, R. 1994. Index of plant hosts of Sclerotinia sclerotiorum. Can. J. Plant Pathol.16:93-108.

6. Carbone, I., and Kohn, L. M. (2001). A microbial population-species interface: nested cladistic and coalescent inference with multilocus data. Mol. Ecol. 10: 947-964.

7. Clarkson, J. P., Phelps, K., Whipps, J. M., Young, C. S., Smith, J. A., and Watling, M. 2004. Forecasting Sclerotinia disease on lettuce: Toward developing a prediction model for carpogenic germination of sclerotia. Phytopathology 94:268-279.

8. Cubeta, M. A., Cody, B. R., Kohli, Y., and Kohn, L. M. 1997. Clonality in Sclerotinia sclerotiorum on infected cabbage in eastern North Carolina. Phytopathology 87:1000-1004.

9. Dillard, H. R., Ludwig, J. W., and Hunter, J. E. 1995. Conditioning sclerotia of Sclerotinia sclerotiorum for carpogenic germination. Plant Dis. 79:411-415.

10. Finch-Savage, W. E., and Phelps, K. 1993. Onion (Allium cepa L.) seedling emergence patterns can be explained by the influence of soil temperature and water potential on seed germination. J. Exp. Bot. 44: 407-414.

11. Hambleton, S., Walker, C., and Kohn, L. M. 2002. Clonal lineages of Sclerotinia sclerotiorum previously known from other crops predominate in 1999-2000 samples from Ontario and Quebec soybean. Can. J. Plant Pathol. 24:309-315.

12. Hao, J. J., Subbarao, K. V., and Duniway, J. M. 2003. Germination of 
Sclerotinia minor and $S$. sclerotiorum sclerotia under various soil moisture and temperature combinations. Phytopathology 93:443-450.

13. Huang, H. C., and Kozub, G. C. 1991. Temperature requirements for carpogenic germination of sclerotia of Sclerotinia sclerotiorum isolates of different geographic origin. Bot. Bul. Acad. Sin. 32:279-286.

14. Kohn, L. M., Stasovski, E., Carbone, I., Royer, J. and Anderson, J. B. 1991. Mycelial incompatibility and molecular markers identify genetic variability in field populations of Sclerotinia sclerotiorum. Phytopathology 81:480-485.

15. McDonald, M. R., and Boland, G. J. 2004. Forecasting diseases caused by Sclerotinia spp. in eastern Canada: fact or fiction? Can. J. Plant Pathol 26:480-488.

16. McLaren, D. L., Conner, R. L., Platford, R. G. , Lamb, J. L., Lamey, H. A., and Kutcher, H. R. 2004. Predicting diseases caused by Sclerotinia sclerotiorum on canola and bean - a western Canadian perspective. Can. J. Plant Pathol. 26:489-497.

17. Mylchreest, S. J., and Wheeler, B. E. J. 1987. A method for inducing apothecia from sclerotia of Sclerotinia sclerotiorum. Plant Pathol. 36:1620.

18. Patterson, C. L., and Grogan, R. G. 1985. Differences in epidemiology and control of lettuce drop caused by Sclerotinia minor and Sclerotinia sclerotiorum. Plant Dis. 69:766-770.

19. Phillips, A. J. L. 1986. Carpogenic germination of sclerotia of Sclerotinia sclerotiorum after periods of conditioning in soil. J. Phytopathol.
116:247-258.

20. Phillips, A. J. L. 1987. Carpogenic germination of sclerotia of Sclerotinia sclerotiorum: A review. Phytophylactica 19:279-283.

21. Sansford, C. E., and Coley-Smith, J. R. 1992. Production and germination of sclerotia of Sclerotinia sclerotiorum. Plant Pathol. 41:154-156.

22. Scherm, H., Savelle, A. T., and Pusey, P. L. 2001. Interactions between chill-hours and degree-days affect carpogenic germination in Monilinia vaccinii-corymbosi. Phytopathology 91:77-83.

23. Sexton, A. C., and Howlett, B. J. 2004. Microsatellite markers revea genetic differentiation among populations of Sclerotinia sclerotiorum from Australian canola fields. Curr. Genet. 46:357-365.

24. Smith, E. A., and Boland, G. J. 1989. A reliable method for the production and maintenance of germinated sclerotia of Sclerotinia sclerotiorum. Can. J. Plant Pathol.11:45-48.

25. Sun, P., and Yang, X. B. 2000. Light, temperature, and moisture effects on apothecium production of Sclerotinia sclerotiorum. Plant Dis. 84:12871293.

26. Walker, A., and Barnes, A. 1981. Simulation of herbicide persistance in soil; a revised computer model. Pest. Sci. 12: 123-132.

27. Young, C. S., Clarkson, J. P., Smith, J. A., Watling, M., Phelps K., and Whipps, J. M. 2004. Environmental conditions influencing Sclerotinia sclerotiorum infection and disease development in lettuce. Plant Pathol. 53:387-397. 